\title{
Osmoregulation and the human mycobiome
}

\author{
Abhishek Saxena and Ramakrishnan Sitaraman * \\ Department of Biotechnology, TERI University, New Delhi, India \\ *Correspondence: minraj@gmail.com \\ Edited and reviewed by: \\ Anton G. Kutikhin, Research Institute for Complex Issues of Cardiovascular Diseases under the Siberian Branch of the Russian Academy of Medical \\ Sciences, Russia
}

Keywords: mycobiome, microbiota, osmoregulation, MAP kinase, Candida spp., stress response, S. cerevisiae

\section{INTRODUCTION}

The last one-and-a half decades have made it amply clear that the human microbiota have a very significant role to play in health and disease. The human body can (or should) be better viewed as a complex ecosystem inhabited by micro-organisms that outnumber human cells 10 to 1 (Ley et al., 2006). However, most research in this field has been focused on the prokaryotic (specifically, bacterial) component of the microbiota. Sampling, in turn, is carried out mostly from sites that are readily accessible (Human Microbiome Project Consortium, 2012). Such sampling might not be genuinely representative of the situation in vivo, even for the bacteria under study. The human alimentary tract is a complex entity that exhibits extensive variation in biological characteristics such as tissue/cell types and secretions, as well as parameters such as temperature, $\mathrm{pH}$, oxygen levels and osmolarity along its entire length. A proteomic study sampling mucosal lavages at multiple colonic sites indicated significant differences in protein profiles between the proximal and distal colon, which was supportive of the concept of their functional and developmental distinctness (Li et al., 2011). The colonization of the human infant by microbes, initially during the process of birth, exhibits an ecological succession of microbial species over time, and plays a prominent role in the maturation of the immune system as well (reviewed in Costello et al., 2012).

The fungal members of the microbiota are not very numerous compared to bacteria. Large-scale metagenomic sequencing of fecal samples of 124 individuals found that only about $0.1 \%$ of genes detected were of eukaryotic origin (Qin et al., 2010). The most commonly encountered genera constituting the fungal microbiota or "mycobiome" (Huffnagle and Noverr, 2013) are Candida, Saccharomyces and Cladosporium (Hoffmann et al., 2013). The bacterial microbiota and a functional immune system are thought to keep the numbers of opportunistic fungal pathogens, such as Candida spp., under check in the absence of any perturbations. However, information from studies of polymicrobial diseases points to subtler adjustments, dependent on environmental conditions and cross-kingdom signals that eventually influence (positively and negatively) modes and rates of growth (reviewed in Peleg et al., 2010). The sensing of, and responses to, biotic and abiotic stimuli by fungi (as in other organisms) involves multiple signaling pathways that can interact to either augment or attenuate one another, as will be discussed below.

\section{OSMOREGULATION AND STRESS RESPONSES IN SACCHAROMYCES CEREVISIAE}

S. cerevisiae, a well-studied fungus, employs two strategies for responding to stress, both involving extensive signaling by MAP kinases (MAPK, alternatively termed SAPK-stress activated protein kinase). The first is stress-specific, e.g., involved in the response to pheromone, spore wall formation and adapting to hyperosmotic conditions etc. (Gustin et al., 1998). The HOG (high osmorality glycerol) pathway that is activated in response to hyperosmotic conditions leads to the accumulation of compatible solutes (glycerol being the most important) and also results in the closure of the aquaglyceroporin Fps1p, enabling retention of glycerol. The HOG pathway functions through two signaling branches. The SLN1 branch involves the two-component membrane sensor protein $\operatorname{Sln} 1 \mathrm{p}$ complexed with Ypdlp and Ssklp that, under hyperosmotic conditions, is unable to inactivate downstream MAPKKKs (functionally redundant Ssk2p and Ssk22p) by phosphorylation. This results in the dephosphorylation of these kinases that phosphorylate the MAPKK Pbs $2 p$ which, in turn, phsophorylates the MAPK Hoglp. Phosphorylated Hoglp moves into the nucleus and interacts with transcription factors such as Hotlp, Msn1p, Msn2p etc. activating the transcription of, among other genes, including those encoding phosphatases (e.g., Ptp2p, Ptp3p) that dephosphosphorylate Hoglp, causing feedback inhibition, limiting the duration of Hoglp activity. The SHO1 branch involves two functionally redundant mucin-like transmembrane osmosensors, Msb2p and Hkrlp, that recruit the Pbs2p MAPKK directly to the cytoplasmic face of the cell membrane as part of a macromolecular complex. Notably, SHO1 branch proteins are shared with other signaling pathways, and it is activated when hyperosmolarity occurs as a result of other cellular responses (reviewed in Hohmann, 2002; Hohmann et al., 2007).

The second strategy for coping with stress is the environmental stress response (ESR) that enables adaptation to the longterm effects of various stresses, in contrast to the more specific and short-term response of other MAPK pathways. The ESR was first described as an increased expression of $\sim 300$ genes and repression of $\sim 600$ genes in response to diverse environmental conditions to which $S$. cerevisiae was subjected (Gasch et al., 2000; Causton et al., 2001). In both these studies, various stress conditions were tested including temperature, hyper- and hypoosmotic shock, oxidative $\left(\mathrm{H}_{2} \mathrm{O}_{2}\right)$ stress etc. Induced genes included those involved 
in a wide variety of processes, including carbohydrate metabolism, detoxification of reactive oxygen species, cellular redox reactions, cell wall modification, protein folding and degradation, DNA damage repair, fatty acid metabolism, metabolite transport, vacuolar and mitochondrial functions, autophagy, and intracellular signaling (Gasch et al., 2000). Genes encoding cytoplasmic ribosomal proteins, tRNA synthases, proteins required for processing rRNAs, and a subset of translation initiation factors were repressed (Causton et al., 2001).

The ESR provides a "cross-protective effect" wherein S. cerevisiae subjected to mild heat stress as the primary stress becomes adapted to higher levels of heat as well as oxidative $\left(\mathrm{H}_{2} \mathrm{O}_{2}\right)$ stresses (Berry et al., 2011). This is especially relevant as stresses under natural conditions don't occur singly or sequentially, but simultaneously. It may seem at first sight that the mild dosage of primary/initial stress is irrelevant, as the ultimate adaptation to the secondary stress(es) is achieved anyway. However, Berry et al. (2011) demonstrated that distinct subsets of genes were activated due to primary and secondary stresses. Earlier work indicated that the cross-protective effect is not universal, but specific to the primary/secondary stress combination (Berry and Gasch, 2008). The major transcription factors mediating the ESR are Msn2p and Msn4p (Berry et al.,
2011). Msn2p and Msn4p (see below) play specific roles depending on the stress combination and are even regulated in a condition-specific manner. Besides, there are other transcription factors activated during the ESR and subsequent "acquired stress resistance," like Hsflp (heat stress), Yap1p (oxidative stress), and Hotlp \& Skolp (hyperosmotic stress), that can also activate Msn2p/4p target genes (Berry and Gasch, 2008).

Adding to the mechanistic complexity of stress responses is recent evidence that Hoglp induces transcription of a long non-coding RNA whose presence is required for chromosome remodeling around the CDC28 gene encoding a cyclindependent kinase and its subsequent induction. This is accompanied by cell cycle delay, and increased Cdc28p levels ensure faster recovery following the stress application (Nadal-Ribelles et al., 2014). Osmoadapated S. cerevisiae exhibit HOG activation upon shmooing in response to pheromone (Baltanás et al., 2013). Hoglp also imposes checkpoints on the mating pathway if pheromone is sensed during a period of hyperosmotic stress. It phosphorylates the protein kinase Rck $2 p$ that inhibits translation of Fus3p (the MAPK of mating pathway) by phosphorylating EF2 (elongation factor 2). Ste50p, a shared component of both the HOG and mating pathways is phosphorylated (and inhibited) by Hog1p (Nagiec and Dohlman,
2012). Thus, the osmoregulation response is not elicited solely by hyperosmolarity per se, but is also influenced by the spatiotemporal modulation of cell-cycle events involving stimuli impinging on other signaling pathways.

\section{THE STRESS RESPONSES AND ADAPTIVE POTENTIAL OF CANDIDA SPP.}

Candida spp. are dimorphic yeasts that occur practically throughout the alimentary tract, and C. albicans and C. glabrata well-known opportunistic pathogens. $C$. albicans can grow as a planktonic unicellular organism (yeast) or as a filamentous organism (hypha). The yeast form is suitable for dissemination, while the hyphal form is more adapted to colonization and biofilm formation. Candida albicans also exhibits parasexuality, in which mating-competent (so-called "opaque") diploid strains mate to form tetraploids, whose progeny later undergo chromosome losses to regenerate the diploid state (Hull et al., 2000; Magee and Magee, 2000). More recent work has demonstrated the existence of a viable and stable haploid form generated by chromosome losses implying that $C$. albicans may not be an "obligate diploid" as originally thought (Hickman et al., 2013). This increases the overall repertoire of genetic diversity in the Candida population, that could confer an adaptive advantage on the organism. Incidentally, these

Table 1 | Proteins involved in osmoadaptation/stress responses as well as other phenotypes in pathogenic fungi.

\begin{tabular}{|c|c|c|}
\hline Gene/Protein & Function summary & References \\
\hline Hog1p & Enhances virulence of $\mathrm{Ca}$ & $\begin{array}{l}\text { Alonso-Monge et al., 1999; } \\
\text { Zhang et al., } 2009\end{array}$ \\
\hline Msn2p & ESR-related transcription factor required for full virulence in entomopathogenic fungi & Liu et al., 2013 \\
\hline Ste11p & Shared MAPKKK in mating response and hyperosmotic stress response, implicated in Cg virulence & Calcagno et al., 2005 \\
\hline Hog1p & $\begin{array}{l}\text { In } \mathrm{Cn} \text {, it antagonizes the effect of Mpk1p (a MAPK) and calcineurin, which promote cell wall integrity } \\
\text { Overactivation of the HOG pathway by fludioxonil (antifungal) results in fludioxinol hypersensitivity } \\
\text { Inhibition of Hog1p in } \mathrm{Cn} \text { is associated with increased ergosterol in the cell membrane, promoting } \\
\text { sensitivity to ergosterol-binding antifungals }\end{array}$ & $\begin{array}{l}\text { Young-Sun Bahn et al., } \\
2012\end{array}$ \\
\hline Cta1p & $\begin{array}{l}\text { Catalase gene of } \mathrm{Cg} \text { regulated by multiple stress-related transcription factors like Msn2p, Msn4p, Skn7p, } \\
\text { Yap1p }\end{array}$ & Cuéllar-Cruz et al., 2008 \\
\hline Ste12p & Transcription factor induced by pheromone and nitrogen starvation in Sc, promotes virulence in $\mathrm{Cg}$ & Calcagno et al., 2003 \\
\hline Slt2p & $\begin{array}{l}\text { The cell wall integrity pathway MAPK in } \mathrm{Cg} \text {; downstream target Rlm1p (a transcription factor) is involved in } \\
\text { micafungin tolerance }\end{array}$ & Miyazaki et al., 2010 \\
\hline Chk1p & $\begin{array}{l}\text { Two component signal transduction protein in Ca; ortholog of oxidative stress sensors (Mak2p and Mak3p) } \\
\text { in S. pombe. Involved in quorum sensing (farnesol response) }\end{array}$ & Kruppa et al., 2004 \\
\hline Mln1p & Msn2p-like protein enabling long-term resistance to weak acid in $\mathrm{Ca}$ & Ramsdale et al., 2008 \\
\hline
\end{tabular}

Sc, Saccharomyces cerevisiae; Ca, Candida albicans; Cg, Candida glabrata; Cn, Cryptococcus neoformans. 
polymorphic transitions caution us that reliance on metagenomic and quantitative approaches to study the gut microbiota may not be adequately reflective of significant, populations and sub-populations that arise transiently by random and/or adaptive mechanisms.

Orthologs of the various MAPK pathway genes and also of the factors involved in the ESR have been discovered in Candida spp. C. albicans is thought to have diverged from $S$. cerevisiae more than 200 million years ago (Kurtzman and Piškur, 2006) The C. albicans ESR (CaESR) is not as extensive in genetic terms as in S. cerevisiae. Only a small number of genes are involved in CaESR ( $\sim 24$ upregulated genes and $\sim 37$ downregulated genes) (Enjalbert et al., 2006; Gasch, 2007). This suggests the absence of a core environmental response/general stress response in C. albicans (Enjalbert et al., 2003). Later studies confirmed that CaMsn4p only weakly complements the inability of an $m s n 2 \triangle m s n 4 \triangle$ double mutant in S. cerevisiae to activate a STRElacZ reporter (STRE-Stress response element) while CaMln1p (Candida albicans Msn2p/Msn4p-like protein) does not complement the defect at all (Nicholls et al., 2004). The transcription factors finally activated in the CaESR have not been conclusively identified. Therefore a complete picture of activation and regulation of ESR in C. albicans is as yet unavailable. However, the number of genes activated/repressed during the CaESR were more in response to oxidative stress $\left(5 \mathrm{mM} \mathrm{H}_{2} \mathrm{O}_{2}\right)$ than in response to osmotic stress $(0.3 \mathrm{M} \mathrm{NaCl})$ and heavy metal stress (0.5 $\mathrm{mM} \mathrm{CdSO}_{4}$ ) (Enjalbert et al., 2006). Other studies have reported that components of stress signaling pathways may be important in virulence, drug tolerance, or quorum sensing, among other phenotypes. Interestingly, Msn2p homologs in entomopathogenic fungi Beauveria bassiana and Metarhizium robertsii augment virulence (Zhang et al., 2009; Liu et al., 2013). Table 1 lists some components of stress signaling known to influence other phenotypes in pathogenic fungi.

\section{CONCLUSIONS}

In contrast to bacteria, a beneficial role for fungi in microbiota-human interactions has not emerged, though their role as opportunistic pathogens (cf. ecologically invasive species) has been extensively studied. The major fungal probiotic in use today, Saccharomyces cerevisiae var. boulardii $(\mathrm{Sb})$, that is not indigenous to the human gut, provides some examples of potential benefits of fungal proteins for the host (Czerucka et al., 1994; Dahan et al., 2003), and can help in the maintenance and/or restoration of hostmicrobiota homeostasis.

The strategies employed by the members of the mycobiome to adapt to changing conditions along the length of the gut and host immune responses may depend significantly on adapting to continuously changing environmental parameters that could also serve as indicators for spatial location, microbiota composition and the physiological state of the host. Signaling pathways that respond to different stimuli are not watertight modules, but can interact in unforeseen ways to produce an integrated behavioral response (Baltanás et al., 2013). Thus, components of the osmoregulatory pathway may also participate in the process of mounting a coordinated response to environmental stiumuli.

\section{ACKNOWLEDGMENTS}

Mr. Abhishek Saxena has successively received research fellowships from the Department of Biotechnology, Government of India (sanction order number BT/PR12598/PBD/26/215/2009, April, 2011 - February, 2014) and from Novozymes and Henning-Holck Larsen foundation (February, 2014 - July, 2014). Mr. Ratan Jha and Dr. Bharati Paliwal of the TERI University library are gratefully acknowledged for their timely and consistent support in procuring some of the references used herein.

\section{REFERENCES}

Alonso-Monge, R., Navarro-García， F., Molero, G., Diez-Orejas, R., Gustin, M., Pla, J., et al. (1999). Role of the mitogen-activated protein kinase Hoglp in morphogenesis and virulence of Candida albicans. J. Bacteriol. 181, 3058-3068.

Baltanás, R., Bush, A., Couto, A., Durrieu, L., Hohmann, S., and Colman-Lerner, A. (2013). Pheromone-induced morphogenesis improves osmoadaptation capacity by activating the HOG MAPK pathway. Sci. Signal. 6:ra26. doi: 10.1126/scisignal.2003312

Berry, D. B., and Gasch, A. P. (2008). Stress-activated genomic expression changes serve a preparative role for impending stress in yeast. Mol. Biol. Cell 19, 4580-4587. doi: 10.1091/mbc.E07-07-0680

Berry, D. B., Guan, Q., Hose, J., Haroon, S., Gebbia, M., Heisler, L. E., et al. (2011). Multiple means to the same end: the genetic basis of acquired stress resistance in yeast. PLoS Genet. 7:e1002353. doi: 10.1371/journal.pgen.1002353

Calcagno, A.-M., Bignell, E., Rogers, T. R., Jones, M. D., Mühlschlegel, F. A., and Haynes, K. (2005). Candida glabrata Ste11 is involved in adaptation to hypertonic stress, maintenance of wild-type levels of filamentation and plays a role in virulence. Med. Mycol. 43, 355-364. doi: 10.1080/13693780 400006088

Calcagno, A.-M., Bignell, E., Warn, P., Jones, M. D., Denning, D. W., Mühlschlegel, F. A., et al. (2003). Candida glabrata STE12 is required for wild-type levels of virulence and nitrogen starvation induced filamentation. Mol. Microbiol. 50, 1309-1318. doi: 10.1046/j.1365-2958.2003.03755.x

Causton, H. C., Ren, B., Koh, S. S., Harbison, C. T., Kanin, E., Jennings, E. G., et al. (2001) Remodeling of yeast genome expression in response to environmental changes. Mol. Biol. Cell 12, 323-337. doi: 10.1091/mbc.12.2.323

Costello, E. K., Stagaman, K., Dethlefsen, L., Bohannan, B. J. M., and Relman, D. A. (2012). The application of ecological theory toward an understanding of the human microbiome. Science 336, 1255-1262. doi: 10.1126/science.1224203

Cuéllar-Cruz, M., Briones-Martin-del-Campo, M., Cañas-Villamar, I., Montalvo-Arredondo, J., Riego-Ruiz, L., Castaño, I., et al. (2008). High resistance to oxidative stress in the fungal pathogen Candida glabrata is mediated by a single catalase, Ctalp, and is controlled by the transcription factors Yap1p, Skn7p, Msn2p, and Msn4p. Eukaryot. Cell 7, 814-825. doi: 10.1128/EC.00011-08

Czerucka, D., Roux, I., and Rampal, P. (1994). Saccharomyces boulardii inhibits secretagoguemediated adenosine 3',5'-cyclic monophosphate induction in intestinal cells. Gastroenterology 106 , 65-72.

Dahan, S., Dalmasso, G., Imbert, V., Peyron, J.-F., Rampal, P., and Czerucka, D. (2003). Saccharomyces boulardii interferes with enterohemorrhagic escherichia coli-induced signaling pathways in T84 cells. Infect. Immun. 71, 766-773. doi: 10.1128/IAI.71.2.766-773.2003

Enjalbert, B., Nantel, A., and Whiteway, M. (2003). Stress-induced gene expression in Candida albicans: absence of a general stress response. Mol. Biol. Cell 14, 1460-1467. doi: 10.1091/mbc.E0208-0546

Enjalbert, B., Smith, D. A., Cornell, M. J., Alam, I., Nicholls, S., Brown, A. J. P., et al. (2006) Role of the Hogl stress-activated protein kinase in the global transcriptional response to stress in the fungal pathogen Candida albicans. Mol. Biol. Cell 17, 1018-1032. doi: 10.1091/mbc.E0506-0501

Gasch, A. P. (2007). Comparative genomics of the environmental stress response in ascomycete fungi. Yeast 24, 961-976. doi: 10.1002/yea.1512

Gasch, A. P., Spellman, P. T., Kao, C. M., CarmelHarel, O., Eisen, M. B., Storz, G., et al. (2000). Genomic expression programs in the response of yeast cells to environmental changes. Mol. Biol. Cell 11, 4241-4257. doi: 10.1091/mbc.11.12.4241 
Gustin, M. C., Albertyn, J., Alexander, M., and Davenport, K. (1998). MAP kinase pathways in the yeast Saccharomyces cerevisiae. Microbiol. Mol. Biol. Rev. 62, 1264-1300.

Hickman, M. A., Zeng, G., Forche, A., Hirakawa, M. P., Abbey, D., Harrison, B. D., et al. (2013). The "obligate diploid" Candida albicans forms mating-competent haploids. Nature 494, 55-59. doi: 10.1038/nature11865

Hoffmann, C., Dollive, S., Grunberg, S., Chen, J., Li, H., Wu, G. D., et al. (2013). Archaea and fungi of the human gut microbiome: correlations with diet and bacterial residents. PLoS ONE 8:e66019. doi: 10.1371/journal.pone.0066019

Hohmann, S. (2002). Osmotic stress signaling and osmoadaptation in yeasts. Microbiol. Mol. Biol. Rev. 66, 300-372. doi: 10.1128/MMBR.66.2.300372.2002

Hohmann, S., Krantz, M., and Nordlander, B. (2007). Yeast osmoregulation. Meth. Enzymol. 428, 29-45. doi: 10.1016/S0076-6879(07)28002-4

Huffnagle, G. B., and Noverr, M. C. (2013). The emerging world of the fungal microbiome. Trends Microbiol. 21, 334-341. doi: 10.1016/j.tim.2013. 04.002

Hull, C. M., Raisner, R. M., and Johnson, A. D. (2000). Evidence for mating of the "asexual" yeast Candida albicans in a mammalian host. Science 289, 307-310.

Human Microbiome Project Consortium (2012). A framework for human microbiome research. Nature 486, 215-221. doi: 10.1038/nature11209

Kojima, K., Bahn, Y.-S., and Heitman, J. (2006). Calcineurin, Mpk1 and Hogl MAPK pathways independently control fludioxonil antifungal sensitivity in Cryptococcus neoformans. Microbiology 152, 591-604. doi: 10.1099/mic.0. 28571-0

Kruppa, M., Krom, B. P., Chauhan, N., Bambach, A. V., Cihlar, R. L., and Calderone, R. A. (2004). The two-component signal transduction protein Chklp regulates quorum sensing in Candida albicans. Eukaryot. Cell 3, 1062-1065. doi: 10.1128/EC.3.4.1062-1065.2004

Kurtzman, C., and Piškur, J. (2006). "Taxonomy and phylogenetic diversity among the yeasts," in Comparative Genomics Topics in Current Genetics, eds. P. Sunnerhagen and J. Piskur (Berlin, Heidelberg: Springer), 29-46.

Ley, R. E., Peterson, D. A., and Gordon, J. I. (2006) Ecological and evolutionary forces shaping microbial diversity in the human intestine. Cell 124, 837-848. doi: 10.1016/j.cell.2006.02.017

Li, X., LeBlanc, J., Truong, A., Vuthoori, R., Chen, S. S., Lustgarten, J. L., et al. (2011). A metaproteomic approach to study human-microbial ecosystems at the mucosal luminal interface. PLoS ONE 6:e26542. doi: 10.1371/journal.pone.0026542

Liu, Q., Ying, S.-H., Li, J.-G., Tian, C.-G., and Feng, M.-G. (2013). Insight into the transcriptional regulation of $\mathrm{Msn} 2$ required for conidiation, multi-stress responses and virulence of two entomopathogenic fungi. Fungal Genet. Biol. 54, 42-51. doi: 10.1016/j.fgb.2013.02.008

Magee, B. B., and Magee, P. T. (2000). Induction of mating in Candida albicans by construction of MTLa and MTLalpha strains. Science 289, 310-313. doi: 10.1126/science.289.5477.310

Miyazaki, T., Inamine, T., Yamauchi, S., Nagayoshi, Y., Saijo, T., Izumikawa, K., et al. (2010). Role of the Slt2 mitogen-activated protein kinase pathway in cell wall integrity and virulence in Candida glabrata. FEMS Yeast Res. 10, 343-352. doi: 10.1111/j.1567-1364.2010.00611.x

Nadal-Ribelles, M., Solé, C., Xu, Z., Steinmetz, L. M., de Nadal, E., and Posas, F. (2014). Control of Cdc28 CDK1 by a Stress-Induced IncRNA. Mol. Cell 53, 549-561. doi: 10.1016/j.molcel.2014. 01.006

Nagiec, M. J., and Dohlman, H. G. (2012). Checkpoints in a yeast differentiation pathway coordinate signaling during hyperosmotic stress. PLoS Genet. 8:e1002437. doi 10.1371/journal.pgen.1002437

Nicholls, S., Straffon, M., Enjalbert, B., Nantel, A. Macaskill, S., Whiteway, M., et al. (2004). Msn2and Msn4-like transcription factors play no obvious roles in the stress responses of the fungal pathogen Candida albicans. Eukaryot. Cell 3, 1111-1123. doi: 10.1128/EC.3.5.1111-1123.2004

Peleg, A. Y., Hogan, D. A., and Mylonakis, E. (2010). Medically important bacterial-fungal interactions. Nat. Rev. Microbiol. 8, 340-349. doi: 10.1038/ nrmicro2313
Qin, J., Li, R., Raes, J., Arumugam, M., Burgdorf, K. S., Manichanh, C., et al. (2010). A human gut microbial gene catalogue established by metagenomic sequencing. Nature 464, 59-65. doi: 10.1038/nature08821

Ramsdale, M., Selway, L., Stead, D., Walker, J., Yin, Z., Nicholls, S. M., et al. (2008). MNL1 regulates weak acid-induced stress responses of the fungal pathogen Candida albicans. Mol. Biol. Cell 19, 4393-4403. doi: 10.1091/mbc.E0709-0946

Young-Sun Bahn, Ko, Y.-J., Maeng, S.-A., Jung, K. W., and Kim, G. B. (2012). Use of the Genes in the HOG, Ras and cAMP Pathway for Treatment of Fungal Infection. US Patent Application Number US 2012/0093817.

Zhang, Y., Zhao, J., Fang, W., Zhang, J., Luo, Z., Zhang, M., et al. (2009). Mitogen-activated protein kinase hogl in the entomopathogenic fungus Beauveria bassiana regulates environmental stress responses and virulence to insects. Appl. Environ. Microbiol. 75, 3787-3795. doi: 10.1128/AEM.01913-08

Conflict of Interest Statement: Work on osmoregulation in S. cerevisiae in our laboratory is supported by a grant from the Department of Biotechnology, Government of India (sanction order number BT/ PR12598/PBD/26/215/2009).

Received: 27 March 2014; accepted: 27 March 2014; published online: 17 April 2014.

Citation: Saxena $A$ and Sitaraman $R$ (2014) Osmoregulation and the human mycobiome. Front. Microbiol. 5:167. doi: 10.3389/fmicb.2014.00167

This article was submitted to Evolutionary and Genomic Microbiology, a section of the journal Frontiers in Microbiology.

Copyright (c) 2014 Saxena and Sitaraman. This is an open-access article distributed under the terms of the Creative Commons Attribution License (CC BY). The use, distribution or reproduction in other forums is permitted, provided the original author(s) or licensor are credited and that the original publication in this journal is cited, in accordance with accepted academic practice. No use, distribution or reproduction is permitted which does not comply with these terms. 